\title{
Problems of radiation safety calculations related to spent nuclear fuel transport casks*
}

\author{
Artem V. Sobolev ${ }^{1}$, Pavel A. Danilov ${ }^{1}$ \\ 1 Obninsk Institute for Nuclear Power Engineering, NRNU “MEPhI”, 1 Studgorodok, Obninsk, Kaluga reg., 249040, Russia \\ Corresponding author: Artem V. Sobolev (SobolevArtem82@gmail.com)
}

Academic editor: Yury Kazansky • Received 14 September 2019 • Accepted 15 December 2019 Published 27 March 2020

Citation: Sobolev AV, Danilov PA (2020) Problems of radiation safety calculations related to spent nuclear fuel transport casks. Nuclear Energy and Technology 6(1): 43-47. https://doi.org/10.3897/nucet.6.51778

\begin{abstract}
The paper discusses the stages of calculating the radiation safety of spent nuclear fuel (SNF) transport packages, in particular, transport casks and some related problems. The problem of describing the source of neutrons and gamma radiation of spent nuclear fuel is shown. For individual designs of fuel assemblies, data are given on isotopes that make the main contribution to the neutron source as well as on gamma rays in nuclear fuel material and structural materials. The authors emphasize the necessity of analyzing the influence of the initial spent fuel parameters on the formation of the radiation spectrum and, therefore, on the radiation situation around the transport casks. Consideration is given to the problem of assessing the attenuation of gamma radiation in calculating protection analytically and using software. Due to the ambiguity of the position of the zone with the highest effective dose value on the SNF transport cask surface, it is indicated that preliminary estimates are required to take into account all radiation sources and their nonuniformities.

All the problems presented in the paper are currently being solved by means of rather complex and voluminous calculations that take a long time. In order to be able to conduct a preliminary assessment of the radiation situation around the transport casks, the authors propose to create a methodology that will determine the type of interrelations between the maximum effective dose and input parameters, such as fuel burnup, decay, fuel composition, protection material in the SNF transport cask, etc. This methodology will make it possible to improve the efficiency of the process of designing the SNF transport casks, avoid possible design errors and, in particular, when used as intended, resolve the issue of the SNF cask loading configuration.
\end{abstract}

\section{Keywords}

SNF transport cask, radiation safety, neutron source, gamma source, radiation protection calculation

\section{Introduction}

Today, ensuring nuclear and radiation safety during the SNF transportation remains an urgent topic due to the growing SNF volumes that must be transported to reprocessing or storage sites. The solution to this problem requires that the SNF transport casks should comply with a number of regulatory documents (PBYA-06-092016, GOST 25461-82, GOST 26013-83, PBYA-06-0096, GOST R51964-2002, NP-053-16, NRB-99/2009, OSPORB-99/2010, IAEA SSR-6): PBYA-06-00-2016, NP-053-16, NRB-99/2009, GOST 25461-82, GOST 26013-83, GOST P51964-2002, GOST R15.301-2016, OSPORB-99/2010, the IAEA TS-R-1 regulations, etc.

* Russian text published: Izvestiya vuzov. Yadernaya Energetika (ISSN 0204-3327), 2019, n. 4, pp. 3-48.

Copyright Sobolev AV, Danilov PA. This is an open access article distributed under the terms of the Creative Commons Attribution License (CC-BY 4.0), which permits unrestricted use, distribution, and reproduction in any medium, provided the original author and source are credited. 
If we consider some of the criteria, the casks must meet the maximum permissible weight and size characteristics. The criticality of the cask contents should not exceed a specified value. Dose rates in the space around the casks should correspond to the maximum permissible values. The surface temperatures of the casks and the main elements of the fuel assemblies should be less than the maximum allowed. The specificity of the research topic makes it rather difficult to find literature that widely covers this issue. This is partly due to the wide range of areas of physics within which this topic is considered, starting with thermal physics and ending with the theory of neutron and gamma radiation transfer. Sources related to this topic describe methods for determining the SNF burnup depth and cooling time as well as methods for describing the radiation environment around the casks.

For a long time in the field of designing SNF transport casks, a large number of structures have been created in Russia (Guskov et al. 2012, Amelin et al. 2010, 2012, Vorontsov et al. 2008). Despite the diversity of designs, we can distinguish the following common components: the cask body, inner and outer lids, trunnions, and dampers. The body and lids contain materials for the predominant attenuation of both neutron radiation and gamma rays. The cask capacity varies widely, for example, for the cask of Patent RF No. 2459295 (Guskov et al. 2012), it is 19 assemblies and, for the new generation TUK-140 packages, it is 42 SFAs. Damping devices are installed on the cask lid and bottom in order to mitigate the effects of external variable loads on the case during transportation, thereby preventing damage to the case and its contents.

\section{Stages of calculated analysis of SNF cask radiation safety and related problems}

Analyzing nuclear and radiation safety of SNF transport casks is rather an intricate problem, since determining the isotopic composition of burnt fuel, the criticality of the cask contents and the dose rate around the casks requires a large number of calculations. A detailed analysis of the above tasks takes a long time. A wide range of types of fuel assemblies, determined by their composition and design, differences in the burnup depth and ways to achieve it, necessitates the creation of a methodology for systematizing the main trends in the formation of gamma radiation and neutron sources in SNF depending on its cooling time, burnup depth and composition. This approach would make it possible to simplify the analysis of the required SNF cooling time or quickly determine the necessary transport cask parameters. Moreover, it could help us develop a certain algorithm with a set of structured data necessary for assessing nuclear and radiation safety in a particular case of SNF loading. This methodology seems to be all the more important if a specific SNF nomenclature is considered when a transport cask is designed; and, when a specific actual SNF loading is performed, as a rule, the SFA parameters differ from the design ones (burnup depth, initial enrichment, fuel assembly design, available burnable absorber, etc.). In such a situation, it is important to be able, without additional lengthy calculations, to determine the number and parameters of loaded SFAs, in which the radiation safety acceptance criteria will not be violated.

To develop this methodology, the following steps are required:

- to estimate, based on existing data or calculations, the sources of gamma rays and neutrons that are formed during the burning of the most common types of fuel in Russian power reactors;

- to analyze the dynamics of changes in the intensity of the sources and their spectral distribution depending on the burnup depth and cooling time;

- to evaluate the contribution of FA materials to the source formation.

Let us now consider the problem of the formation of a source of neutrons and gamma rays. According to existing studies, neutron sources for uranium and MOX fuel irradiated in a VVER-1000 reactor with a three-year cooling time are formed due to the set of isotopes presented in Tab. 1. As can be seen from the table, neutron sources are formed mainly due to $\mathrm{Cm}-244$.

A gamma source during SNF cooling for 3-5 years is formed due to the isotopes ${ }^{85} \mathrm{Kr},{ }^{90} \mathrm{Sr},{ }^{90} \mathrm{Y},{ }^{106} \mathrm{Rh},{ }^{125} \mathrm{Sb}$, ${ }^{134} \mathrm{Cs},{ }^{137} \mathrm{Cs},{ }^{137 \mathrm{~m}} \mathrm{Ba},{ }^{144} \mathrm{Ce},{ }^{144} \mathrm{Pr},{ }^{147} \mathrm{Pm},{ }^{154} \mathrm{Eu},{ }^{155} \mathrm{Eu}$, which are fission products (Opalovsky 2007). However, when analyzing radiation safety of the cask, one should take into account the irradiation of not only fuel but also structural materials. It turns out that in a number of cases, the main contribution to the dose rate is made by ${ }^{60} \mathrm{Co}$, which is contained in the stainless steel of the FA bottom fittings. The difficulty in estimating the dose rate from ${ }^{60} \mathrm{Co}$ is associated with the fact that there is no explicit normalization of the amount of ${ }^{59} \mathrm{Co}$ in the stainless steel composition of which the FA bottom fittings are made. According to GOST 5632-72 and GOST 5632-2014 (GOST 563272 , GOST 5632-2014), the cobalt content is not explicitly standardized for austenitic steel grade $12 \mathrm{X} 18 \mathrm{H} 10 \mathrm{~T}$, and the limiting value of the mass fraction of $0.5 \%$ is given for nickel and iron-nickel alloys to which this steel does not belong. Therefore, there is a need to obtain information on the amount of ${ }^{59} \mathrm{Co}$ in steel grades used for manufacturing FA structural materials.

Despite the existence of a list of isotopes of gamma and neutron sources for a specific cooling time and burnup depth, there is no generalized information about the change in the group of isotopes and their contribution to the formation of gamma sources when these parameters change. From here follows the first important problem, i.e., the determination of the sources of neutron and gamma radiation for fuel assemblies with the values of fuel burnup, cooling time and compositions used at NPPs. 
Table 1. Isotopes determining a neutron source during threeyear cooling (Opalovsky 2007).

\begin{tabular}{lcccccc}
\hline Pu-238 & Pu-240 & Pu-242 & Cm-242 & Cm-244 & Cm-246 & Cf-252 \\
\hline$\sim 0.1 \%$ & $\sim 0.2 \%$ & $\sim 0.1 \%$ & $\sim 1 \%$ & $\sim 96 \%$ & $\sim 1 \%$ & $\sim 1 \%$ \\
\hline
\end{tabular}

When calculating fuel burnup, it is possible to use software systems that calculate it either by solving a system of point burnup equations or taking into account the fuel geometry in the material, where it is possible to divide the burnable material into separate components that burn up in a specific neutron flux. It can take a large amount of time to form a new detailed model for each case or to calculate it using a computer. Therefore, it becomes necessary to solve the second problem, i.e., assessing the effectiveness of replacing a detailed model with a simplified one using homogenization. The solution to this problem is important both for calculating radiation sources and, therefore, calculating dose rates on the transport cask surfaces.

It is also necessary to clearly define a set of materials that are most suitable for protection against both neutron and gamma radiation. The protection material and its geometry are selected individually for each type of gamma radiation source. If we consider a point source, the expression characterizing the equivalent dose rate at the point behind the shield will look as follows (Gusev 1989, Mashkovich and Kudryavtseva 1995):

$$
\dot{H}=\frac{A a \Gamma_{\delta}}{b^{2}} e^{-\mu d} B_{d}^{p . s .}\left(E_{0}, \mu d, Z\right)
$$

where $A$ is the activity, $\mathrm{Bq} ; b$ is the distance from the point source to the dose calculation point, m; $a=1,09 \mathrm{~Sv} / \mathrm{Gy}$ is the transition coefficient from the air kerma rate to the equivalent dose rate; $\Gamma_{\delta}$ is the constant kerma, $\mathrm{aGy}^{\circ} \mathrm{m}^{2} /$ $(\mathrm{s} \times \mathrm{Bq}) ; B_{\mathrm{d}}^{\text {p.s. }}$ is the dose accumulation factor of a point isotropic source; $d$ is the protection thickness, cm; $\mu$ is the linear attenuation factor.

At present, the attenuation of gamma and neutron radiation is most often calculated using the Monte Carlo-based software (Opalovsky et al. 2004). This obviates the need for cumbersome analytical estimates. Based on numerical calculations, it is possible to determine the most optimal configurations for the transport cask case in terms of attenuation of radiation at the stage of solving design problems when creating a new type of cask. This procedure enables solving the problem associated with determining the optimal transport cask protection configurations for specific SFAs in view of varying parameters of a given type of fuel assemblies.

Due to uneven axial fuel burnup and the presence of ${ }^{60} \mathrm{Co}$ in the FA bottom fittings, the overall picture of the effective dose rate is uncertain and the position of the maximum value level can change. However, when designing transport casks, it is necessary to have information in advance about the region with the highest radiation level, which will make it possible to orient the cask design to the greatest attenuation of radiation at this level. For example, in Fig. 2, the region with the highest effective dose

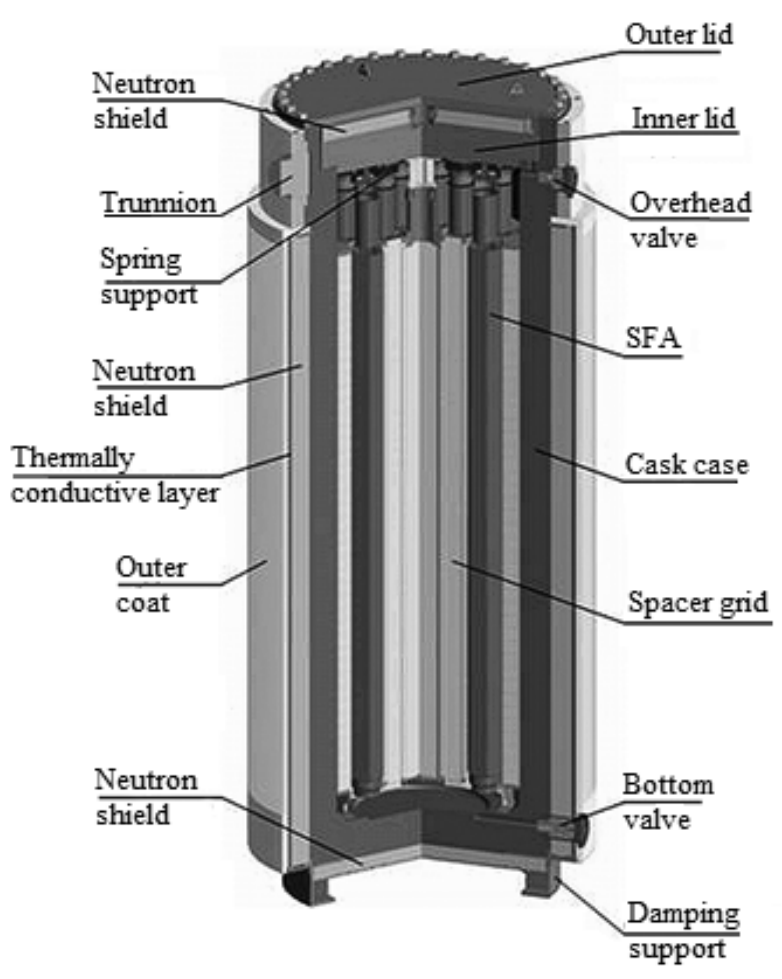

Figure 1. Block diagram of a transport cask for the transportation and storage of spent nuclear fuel (the author is JSC Design Bureau for Special Machine-Building) (Vasilyev et al. 2019).


Actual data for SFA: $B=42-43 \mathrm{MW}$ day $/ \mathrm{kg}, \mathrm{t}_{\text {cool }}=4-5$ years

- Calculated data for the SFA: $B=43 \mathrm{MW}$ day $/ \mathrm{kg}, \mathrm{t}_{\text {cool }}=4-5$ years, $x=4.4 \%$

Figure 2. An example of the uneven axial effective dose rate for transport casks. 
value corresponds to the level where the FA top fittings are located, which are sources of gamma radiation due to the accumulated ${ }^{60} \mathrm{Co}$.

To fully cover the considered problem and its causes, we shall draw up a so-called 'root cause analysis diagram' (Fig. 3). The main problem in this case is the assessment of the effective dose on the transport cask surface. The above diagram may include other more detailed features that affect the final parameter. Therefore, in order to optimize the procedure for estimating the effective dose on the transport cask surface, it is necessary to create a methodology that provides an assessment of the type of relationship between the effective dose and the parameters indicated in Fig. 3., i.e., to make a regression analysis.

The results of the regression analysis will make it possible to use the obtained dependences for initial estimates of a specific actual load of transport casks. Since readymade dependences will be given, the estimation procedure will become more convenient and simple. Initially, the dependences can be obtained on the basis of numerical calculations of models with subsequent verification based on performed measurements. Since the scale of SFA shipments will grow due to the construction of new units, the emergence of a convenient estimation technique will accelerate the process of calculating radiation safety of SNF in transport casks and ensure radiation safety when assemblies with configurations different from the design are loaded into transport casks.

The authors prepared the design model - TUK-141O (Fig. 4) - for the transportation of SFAs of VVER-1000 reactors. To calculate the dependence of the effective dose on the transport cask surface on the input parameters, it is necessary to carry out calculations at a known load and compare them with the measurement results. This will make it possible to validate the calculation model and, if necessary, refine it. At the next stage, in accordance with the diagram, calculations will be performed for TUK1410 with the varied fuel parameters in order to analyze the behavior of the effective dose and estimate the maximum load in the transport cask depending on fuel burnup, type, enrichment, and cooling.

\section{Conclusion}

Based on the above, conclusions can be drawn regarding the problem of the calculation analysis of radiation safety of SNF transport casks. Justifying radiation safety is a complex and multi-stage process. Each calculation is unique, since the set of input parameters is quite extensive

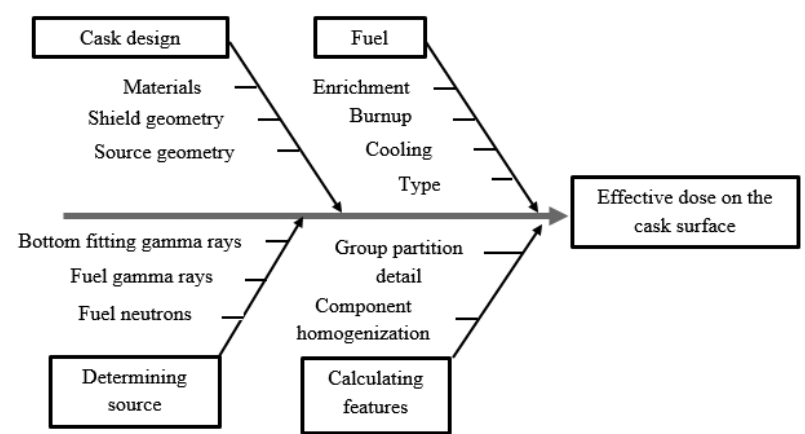

Figure 3. Root cause analysis diagram for assessing the effective dose on the transport cask surface.

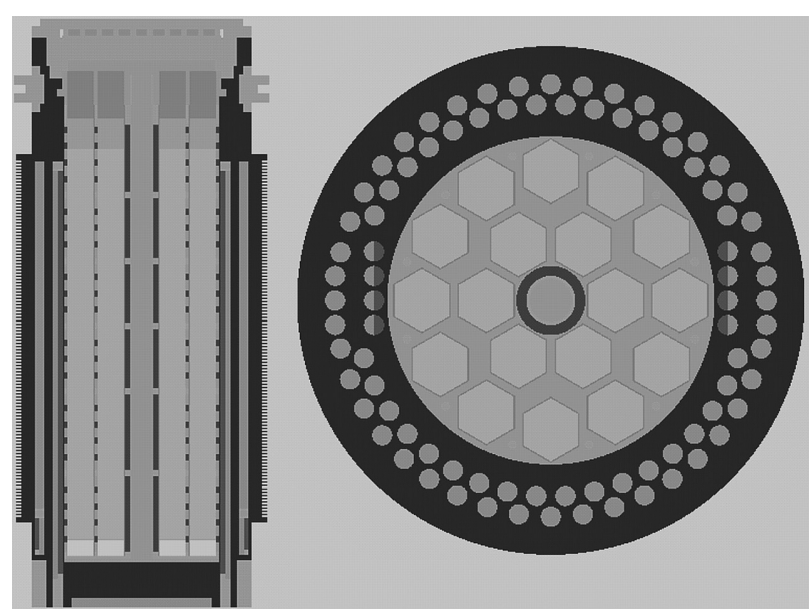

Figure 4. Vertical and horizontal sections of the TUK-141O design model.

and variable, and an analysis of the type of their influence on the radiation situation around the cask was not carried out. To carry out a detailed calculation, it is necessary to have resources for modeling and calculating fuel burnup and assessing the situation around the cask. If these tools are available, the analysis takes a long time, slowing down the design and justification of cask radiation safety and even more so when the actual load of transport casks is determined on site. To solve this problem, it was proposed to create a methodology that will allow preliminary calculations of the effective dose on the surface based on the identified dependences on the input parameters (fuel burnup, cask materials, fuel cooling, etc.). The type of dependencies can be obtained on the basis of the analysis of a large number of calculated data when any parameter is varied while the others remain unchanged. If this technique is successfully developed, a useful tool will be created that can be continuously supplemented and modernized.

\section{References}

- Amelin AM, Grunin VV, Guskov VD, Dolbenkov VG, Zaytsev BI, Sivkov AN, Khodasevich KB (2010) Patent RF No. 2400843. Trans-

port package for transporting and storage spent nuclear fuel. Patent Rossii [Russia's Patent], no. 2400843, bull. no. 23. [in Russian] 
- Amelin AM, Vorontsov VV, Guskov VD, Dolbenkov VG, Zaytsev BI, Korotkov GV, Sivkov AN, Khodasevich KB (2012) Patent RF No. 2465662. Container for transporting and/or storing spent nuclear fuel. Patent Rossii [Russia's Patent], no. 2465662, bull. no. 30. [in Russian]

- GOST 25461-82 (1988) Transport packages for spent fuel assemblies of nuclear reactors. Requirements for methods of calculating nuclear safety. https://meganorm.ru/Data/77/7743.pdf [accessed June 17, 2019] [in Russian]

- GOST 26013-83 (1984) Transport packages for spent fuel assemblies of nuclear reactors. General technical requirements. https:// meganorm.ru/Index2/1/4294828/4294828423.htm [accessed June 17, 2019] [in Russian]

- GOST 5632-2014 (2014) Alloyed stainless steels and corrosion-resistant, heat-resistant alloys. https://meganorm.ru/Data/581/58175. pdf [accessed June 17, 2019] [in Russian]

- GOST 5632-72 (2015) High-alloy steels and corrosion-resistant, heat-resistant alloys. https://meganorm.ru/Data/421/42169.pdf [accessed June 17, 2019] [in Russian]

- GOST R51964-2002 (2002) The packages of spent nuclear fuel. Types and basic parameters. https://meganorm.ru/Data/61/6109.pdf [accessed June 17, 2019] [in Russian]

- Gusev NG (1989) Ionizing Radiation Protection. Vol. 1. Physical Basics of Radiation Protection. Moscow. Energoatomizdat Publ., 512 pp. [in Russian]

- Guskov VD, Amelin AM, Vorontsov VV, Kapustkina OO, Khodasevich KB, Zaytsev BI, Sivkov AN (2012) Patent RF No. 2459295. Transport package for spent fuel assemblies of nuclear reactors. Patent Rossii [Russia's Patent], no. 2459295, bull. no. 23. [in Russian]

- IAEA SSR-6 (2012) Regulations for the Safe Transport of Radioactive Material. https://www-pub.iaea.org/MTCD/Publications/PDF/ P1570r_web.pdf [accessed June 17, 2019] [in Russian]

- Mashkovich VP, Kudryavtseva AV (1995) Ionizing Radiation Protection: Reference Book. Moscow. Energoatomizdat Publ., 496 pp. [in Russian]
- NP-053-16 (1995) Federal norms and rules in the field of the use of atomic energy "Safety rules for the transport of radioactive materials". https://meganorm.ru/Data2/1/4293748/4293748284.htm [accessed June 17, 2019] [in Russian]

- NRB-99/2009 (2009) Radiation safety standards. https://meganorm. ru/Data1/56/56325/index.htm [accessed June 17, 2019] [in Russian]

- Opalovsky VA (2007) Development of Computational Method for Modeling the Radiation Characteristics of Irradiated Nuclear Fuel. Extended Abstract of Cand. Sci. (Engineering) Dissertation. Moscow. MEPhI Publ., 20 pp. [in Russian]

- Opalovsky VA, Tikhomirov GV, Kryuchkov EF (2004) Method of calculating the radiation situation around a container with irradiated nuclear fuel. Izvestiya vuzov. Yadernaya energetika [News of Higher Educational Institutions. Nuclear Energy] 4: 63-69. [in Russian]

- OSPORB-99/2010 (2010) Basic sanitary rules for radiation safety https://meganorm.ru/Data2/1/4293816/4293816468.htm [accessed June 17, 2019] [in Russian]

- PBYA-06-00-96 (2013) Basic industry nuclear safety rules for the use, processing, storage and transportation of nuclear hazardous fissile materials. https://meganorm.ru/Data2/1/4293842/4293842541. htm [accessed June 17, 2019] [in Russian]

- PBYA-06-09-2016 (2016) Basic nuclear safety rules for the production, use, processing, storage and transportation of nuclear fissionable materials. https://meganorm.ru/Data2/1/4293746/4293746881. pdf [accessed June 17, 2019]. [in Russian]

- Vasilyev AS, Romanov AV, Shchukin PO (2019) Strategic pathways of creating environmentally friendly transport packages for transporting and storing spent nuclear fuel. Inzhenerny Vestnik Dona. Elektronny Nauchny Zhurnal [Engineering Bulletin of the Don. Electronic scientific journal]. http://www.ivdon.ru/magazine/archive/n3y2012/910 [accessed June 17, 2019] [in Russian]

- Vorontsov VV, Guskov VD, Zaytsev BI, Khodasevich KB (2008) Patent RF No. 2324241. Container for transporting and/or storing spent nuclear fuel. Patent Rossii [Russia’s Patent], no. 2324241, bull. no. 13. [in Russian] 